\title{
The Development of Soft Skills for Professional Activity (Trend or Reality)
}

\author{
Valentyn Korniienko \\ ORCID 0000-0001-7070-5127 \\ Masters (Design Automation Department) \\ Kharkiv National University of Radioelectronics \\ Kharkiv, Ukraine \\ valentyn.korniienko1@nure.ua
}

\author{
Olha Myttseva \\ ORCID 0000-0002-3398-2982 \\ dept. of philosophy \\ Kharkiv National University of Radioelectronics \\ Kharkiv, Ukraine \\ olha.myttseva@nure.ua
}

\begin{abstract}
Nowadays it's hard to distinguish between hard and soft skills requirements. A potential candidate can be requested for having both of them. The article provides the summarized overview of both skill kinds.
\end{abstract}

\section{Keywords—soft-skills, hard-skills, human recruitment}

\section{INTRODUCTION}

The reality for many specializations according to the requirements specified in the vacancy, increasingly includes one of the items developed set of soft-skills, while not always correlating with other requirements related to the technical requirements for the vacancy (so-called hardskills). Sometimes, the interview stage separately includes the stage of communication in an informal environment or a separate communication with the organization's psychologist and HR specialist to determine the level of possible interaction in the team of a potential new colleague. Does the trend have a lasting rationale, or is it just a lawsuit and new fashion winds from the employment procedure?

\section{SOFT SKILLS AND HARD SKILLS}

Soft-skills terminology means skills that are not tied to a specific profession and allow you to interact normally and flexibly in a team and justify your opinion. The terminology is not new, as the term was added to the business environment only in the late 1990s, and research on the subject began in the 1960s. Currently, the need for soft skills has increased due to the rapid reduction in the relevance of a particular area of knowledge. Therefore, on the one hand, the presence of soft skills in an employee makes him more valuable, because the skills related to the speed of learning and learning new knowledge are more relevant than the accumulated knowledge. This is at first glance.

What skills should be highlighted? First, communication skills allow you to work in a team and negotiate between them. Secondly, self-organization skills and creative skills. The ability to work with information is necessary today because of its large number. Stress tolerance is currently relevant due to the speed of life processes and requires the ability to quickly maintain a normal level of performance.

\section{AVAILABLE RESEARCH}

As for research in soft-skills fields. Back in 2008, Higher Education in Europe published an article proving that flexible skills are as much a part of professional competencies as rigid ones. The author believes that modern education should include soft skills training - so that graduates meet the requirements of the labor market. The International Journal of Managing Projects in Business has published a study showing that the main difficulties in working on a project are created by the human factor. Researchers summarize the importance of soft management skills.

Gina Watson Mitchell in her dissertation analyzes the survey data and recommends that universities include the development of flexible skills in their curricula.

However, the most complete list and categories were formed by the World Economic Forum in the Future of Jobs report. The study involved global employers-drivers of various industries and identified 35 flexible skills. All flexible skills were divided into 3 key groups: abilities, basic skills, cross-functional skills.

According to the publication CareerAddict, the TOP-20 soft-skills have been identified, which are currently relevant for a potential employee.[1] Consider a few of them:

Work etiquette - excellent work ethic is vital for success throughout working life. A constant desire to learn and progress is necessary. This does not mean that you need to dedicate your entire life to your occupation, but the need to complete your current tasks and some that are not included in the current list of job descriptions to help a teammate.

Flexibility - Being focused on one subject area, the transition between different projects will be difficult. Requires the ability to prioritize to identify pressing issues.

Leadership - Leadership is defined as the ability to take initiative when possible. It is the act of leading a group of people, delegating responsibilities, managing others, and providing guidance for the effective operation of a business or unit. Even though a colleague does not hold a leadership position (for example, he is not a manager), management itself shows a willingness to take control of the situation, effectively manage and support their colleagues.

Self-motivation $\neg$ despite the passion for work, there may be times when the motivation to perform it is lost. As a specialist of the 21st century, and especially in 2020-2021, everyone should have a thirst for self-motivation to complete tasks on time.

Decision making - the ability to make the right and effective decisions quickly is a requirement that can be met 
by every employer. Effective decision-making is to use a combination of intuition and logical reasoning to choose a possible course of action from the proposed options. It also concerns the correct judgment of the situation, conclusions, and practical solution of the problem.

Innovation - it doesn't matter if the employee is in a managerial or a working role - creativity is the basis for a company's sustainable long-term development (also known as a company roadmap). The development of this soft skill is necessary and can be listed in the resume as one of the characteristics that can affect the employer.

\section{HARD SKILLS PART}

Consider the concept of hard skills, and what distinguishes them from soft skills. Currently, the main hard skills that can be identified are:

- Knowledge of foreign languages.

- Speed of computer work, knowledge of typical software packages.

- Knowledge of programming languages and work automation.

Hard skills differ from soft skills in their specification of competencies within a particular specialty. If soft skills are cross-specialization knowledge (knowledge that can be applied in any specialty) and affect the movement in the company and development. As typical examples, the expected hard skills from specialists can be given. For example, for a project manager, the main skills will be the availability of communication skills and knowledge of the subject area of the product.[2] A business analyst needs knowledge of investment analysis methods, skills in working in Agile teams, the ability to process detailed reports and work with large amounts of information. A typical software developer needs knowledge of the appropriate programming language, database skills, analytical thinking, and basic knowledge of technical English.[3]

As for the requirements of a particular specialist - the interview may include separate stages, as mentioned earlier. Sometimes, this can be two or more time-separated interviews in which the specialist will also be asked to communicate with the development team and management that will accompany the colleague.

Considering the development of soft skills, for the time being, it should be noted that their number in a particular job will vary. Depending on the size of the company, product, and focus, it is possible to determine the relationship and the need for communication between colleagues. If you look at the four examples - a large company with outsourcing projects designed for large teams, a product company with small projects for 1-2 people, a large outsourcing company with small projects, and a research and production enterprise with areas related to research and individual work.

In the first example, it is necessary to have a developed set of soft skills due to the large amount of communication that can take place. In the case of a product company with small projects, soft skills may be less important and the advantage of hard skills among professionals may be significant, thus taking advantage of skills that directly affect the company's profits (more projects - more budget). In the case of a large outsourcing company with small projects, the distribution will be almost half, namely, the requirements of a specialist in soft and hard skills will be similar, perhaps with a slight advantage towards hard skills. The last example, namely NVP with scientific individual research can be a demonstration of full hard-skills enterprise, where the need for external communication is minimal, and interaction between colleagues and the transfer of test results or intermediate results can be formalized according to DSTU norms and standards.

\section{CONCLUSION}

Thus, today the development of soft skills is necessary in the case of employment in large companies, where they can directly affect the advancement in the career ladder. In the case of employment in a company where preference is given to employees who can fully meet the requirements of professional skills, the availability of soft skills can be a nice bonus, but not the main parameter in the selection of potential candidates.

\section{REFERENCES}

[1] What is the necessity of soft-skills? [Online]. Available: https://skillbox.ru/media/growth/chto_takoe_soft_skills_i_kak_ikh_ra zvit/ [Accessed: 10- May- 2021]

[2] Top 20 Soft Skills Employers Look for in the Workplace [Online]. Available: https://www.careeraddict.com/soft-skills [Accessed: 10May- 2021]

[3] Spftskills examples for an employee [Online]. Available: https://inskills.space/hard-skills-primery-kompetenczij-dlya-raboty/ [Accessed: 10- May- 2021] 